\title{
Lamina-Independent Lamins in the Nuclear Interior Serve Important Functions
}

\author{
T. Dechat, K. Gesson, and R. Foisner \\ Max F. Perutz Laboratories, Department of Medical Biochemistry, Medical University of Vienna, \\ Vienna 1030, Austria \\ Correspondence: roland.foisner@meduniwien.ac.at
}

\begin{abstract}
Nuclear lamins were originally described as the main constituents of the nuclear lamina, a filamentous meshwork closely associated with the inner nuclear membrane. However, within recent years, it has become increasingly evident that a fraction of lamins also resides throughout the nuclear interior. As intermediate-filament-type proteins, lamins have been suggested to fulfill mainly structural functions such as providing shape and mechanical stability to the nucleus. But recent findings show that both peripheral and nucleoplasmic lamins also have important roles in essential cellular processes such as transcription, DNA replication, cell cycle progression, and chromatin organization. Furthermore, more than 300 mutations in the gene encoding A-type lamins have been associated with several human diseases now generally termed laminopathies and comprising muscular dystrophies, lipodystrophies, cardiomyopathies, and premature aging diseases. This review focuses on the laminaindependent pool of lamins in the nuclear interior, which surprisingly has not been studied in much detail so far. We discuss the properties and regulation of nucleoplasmic lamins during the cell cycle, their interaction partners, and their potential involvement in cellular processes and the development of laminopathies.
\end{abstract}

The nucleus of an eukaryotic cell can be roughly divided into two major compartments: the nuclear envelope (NE), which is composed of the outer and inner nuclear membrane (ONM and INM, respectively), nuclear pore complexes (NPCs) and nuclear lamina, and the nucleoplasm, which contains the chromatin, various structural subcompartments, and soluble nuclear components (for review, see Pederson 2010). In contrast to the well-characterized cytoskeletal framework in the cytoplasm, consisting of actin filaments, intermediate filaments (IFs), and the microtubules, still little is known about the structural scaffold within the nucleus, often termed the nucleoskeleton. The best-studied component of the nucleoskeleton is a filamentous protein meshwork at the nuclear periphery, the nuclear lamina (for review, see Gruenbaum et al. 2005), but the structural organization of the nuclear interior is poorly understood. The main components of the nuclear lamina and probably also of the internal nucleoskeletal structures are type-V IF proteins, the nuclear lamins (Gerace and Blobel 1980; Aebi et al. 1986; Hozak et al. 1995; Barboro et al. 2002).

Nuclear lamins are classified into A and B types, based on sequence homologies, expression patterns, and structural, biochemical, and dynamic properties (for reviews, see Broers et al. 2006; Verstraeten et al. 2007; Dechat et al. 2010). All A-type lamins in mammals, of which the major isoforms are lamin $\mathrm{A}$ and $\mathrm{C}$, are derived from a single gene, $L M N A$, by alternative splicing. In contrast, the two major B-type lamin isoforms in mammals, lamin B1 and B2, are encoded by different genes, $L M N B 1$ and $L M N B 2$, respectively. Whereas at least one B-type lamin is expressed in all metazoan cells, A-type lamins are found only in vertebrates (with the exception of Drosphila melanogaster, which also expresses an A-type lamin), and their expression is developmentally regulated (for reviews, see Melcer et al. 2007; Dechat et al. 2008). Regarding the latter, A-type lamins, for example, are not expressed in human and mouse embryonic stem cells (Constantinescu et al. 2006; Butler et al. 2009) and during mouse embryogenesis until day 10-12 (Stewart and Burke 1987; Rober et al. 1989). In particular, A-type lamins have been linked to various diseases that are collectively called laminopathies and include skeletal muscle diseases (e.g., Emery-Dreifuss muscular dystrophy [EDMD]), cardiomyopathies, lipodystrophies, and premature aging syndromes (e.g., Hutchinson-Gilford progeria syndrome [HGPS]) (for review, see Worman et al. 2010).

On the molecular level, lamins display the typical tripartite structure common to IFs, consisting of an $\alpha$-helical rod domain, a globular amino-terminal head, and a carboxy-terminal tail domain (Fig. 1) (for review, see Herrmann et al. 2009). Within their amino terminus, lamins contain a nuclear localization signal (NLS) located right after the rod domain (Loewinger and McKeon 1988) and a structural motif similar to an S-type immunoglobulin (Ig) fold (Dhe-Paganon et al. 2002; Krimm et al. 2002). In addition, lamin $\mathrm{A}$ and $\mathrm{B}$-type lamins possess a CAAX box at their carboxy-terminal end that leads to their excessive posttranslational processing (for review, see Rusinol and Sinensky 2006). This processing involves the farnesylation and carboxymethylation of the cysteine residue and removal of the -AAX tripeptide and appears to be important for the close association of lamins with the INM (Krohne et al. 1989; Rusinol and Sinensky 2006; Dechat et al. 2007). Although B-type lamins remain farnesylated and carboxymethylated and are thus tightly membrane associated, lamin A is further processed by the 


\section{Disease-causing lamin A/C mutations}

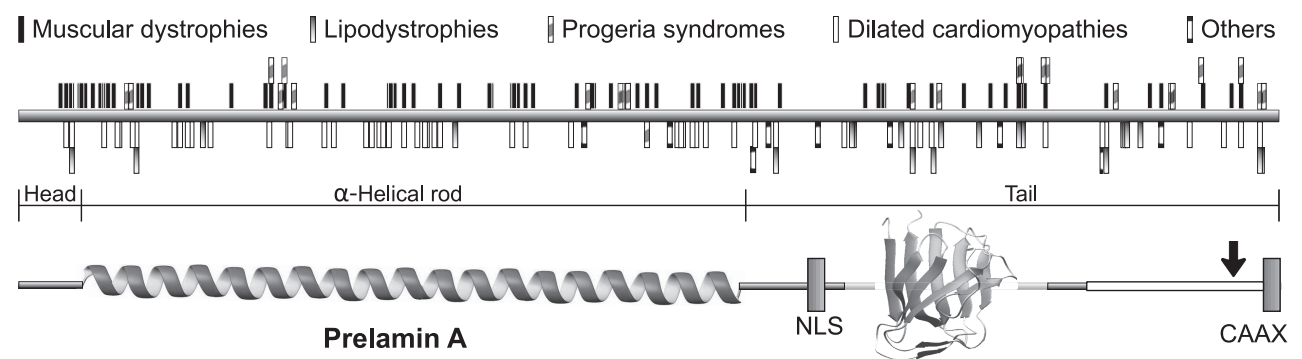

$\lg$ fold

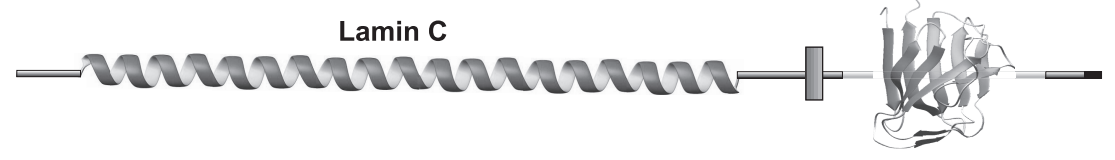

Posttranslational modifications of lamin A/C

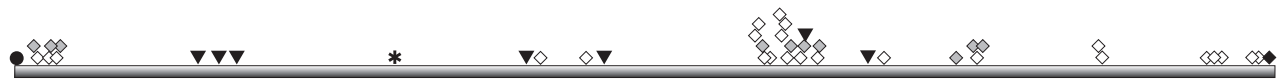

- Amino acetylmethionine $\diamond$ Phosphothreonine $\diamond$ Phosphoserine $\nabla$ N6-Acetyllysine $*$ SUMO $\bullet$ Farnesyl/carboxymethyl

Identified binding domains within lamin A/C

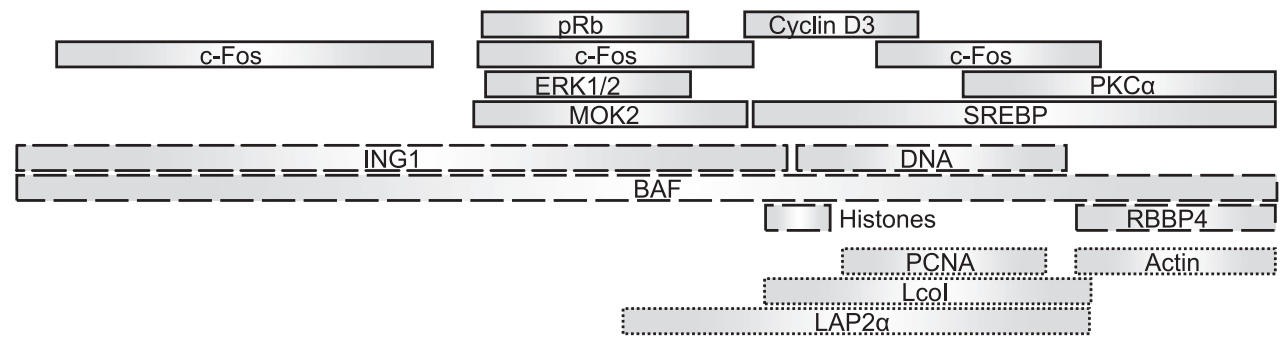

Figure 1. Molecular domain organization of prelamin A and lamin C. (NLS) Nuclear localization signal. The CAAX motif is posttranslationally modified. (Arrow) Site of the last proteolytic cleavage by Zmpste24/FACE1. (White) Lamin A- and (black) lamin Cspecific regions at the carboxyl terminus. Shown are the position of disease-causing mutations (top) and posttranslational modifications (bottom) as well as reported interaction domains for lamin A/C-binding partners (bottom) within the lamin polypeptide. Mutation sites are derived from the UMD-LMNA database (http://www.umd.be/LMNA/W_LMNA/gene.shtml). Shown are only missense mutations, in-frame deletions and insertions, and splice mutations leading to HGPS. Data for modifications were obtained from the UniProt database (http://www.uniprot.org/). (Bottom) Interaction partners were grouped into proteins involved in (continuous frames) gene expression, signaling, and cell cycle control; (dashed frames) chromatin organization; and (dotted frames) other processes. See text for details and references.

zinc metalloprotease Zmpste24/FACE1 (Corrigan et al. 2005). In this last step, an additional 15 amino acids are cleaved off of the carboxyl terminus of lamin A, including the farnesylated/carboxymethylated cysteine residue. Therefore, lamin A can also be found in a membrane-independent nucleoplasmic pool (see below).

On the structural level, lamins form parallel and in-register coiled-coil dimers that further associate in a head-totail fashion to form polar polymers (Heitlinger et al. 1991; Stuurman et al. 1998). In vitro, these polymers assemble into higher-order structures including $\sim 10$-nm filaments and paracrystalline structures (Heitlinger et al. 1991; Stuurman et al. 1996; Karabinos et al. 2003; Foeger et al. 2006; Ben-Harush et al. 2009). However, little is known about the assembly, composition, and structure of lamin polymers in cells, both at the NE and in the nuclear interior. Within past years, increasing evidence has accumu- lated that nucleoplasmic lamins are not only assembly intermediates before their integration into the peripheral nuclear lamina but they also represent a distinct pool of lamins that is tightly regulated and serves important functions in many cellular processes. In this review, we focus on this newly emerging concept and discuss the structure, regulation, dynamics, and functions of the lamina-independent pool of lamins. We also discuss the role of laminbinding proteins in the regulation of the structure and function of nucleoplasmic lamins.

\section{STRUCTURE AND DYNAMICS OF NUCLEOPLASMIC LAMINS}

Unlike cytoplasmic IFs, which are well characterized by various light and electron microscopy methods (Svitkina et al. 1995; Eriksson et al. 2009), lamin structures in the nu- 
cleus have only been analyzed and microscopically visualized at higher resolution in a few studies. At the nuclear periphery, the reported lamina structures range from a regular meshwork of $\sim 10$ - to 15-nm filaments in Xenopus oocyte germinal vesicles and in vitro assembled sperm pronuclei (Aebi et al. 1986; Zhang et al. 1996; Goldberg et al. 2008) to more irregular meshworks described in mammalian cells (Belmont et al. 1993; Schermelleh et al. 2008; Shimi et al. 2008). These meshworks are most likely formed by separate A- and B-type lamin networks that overlap and interact with one another (for review, see Dechat et al. 2010). The structural properties, assembly state, and composition of intranuclear lamins, however, remain an enigma. Although a few ultrastructural studies suggest lamin filaments or a lamincontaining lattice throughout the nuclear interior (Hozak et al. 1995; Barboro et al. 2002, 2010), indirect immunofluorescence microscopy and analyses of green fluorescent protein (GFP)-tagged lamins in cells reveal either a uniformly nucleoplasmic lamin "veil" or intranuclear lamin foci (Bridger et al. 1993; Moir et al. 1994, 2000; Broers et al. 1999; Kennedy et al. 2000; Muralikrishna et al. 2004, Naetar and Foisner 2009). Regarding the latter, such foci may not be mistaken with invaginations of the nuclear membrane described in cultured cells (Fricker et al. 1997; Broers et al. 1999).

Fluorescence recovery after photobleaching (FRAP) and fluorescence correlation spectroscopy (FCS) analyses of ectopically expressed GFP-tagged lamins in cells revealed a much higher mobility of nucleoplasmic versus peripheral A-type lamins, which are more or less immobile, indicating that A-type lamins within the nuclear interior reside in a lower assembly state compared to those integrated in the nuclear lamina (Broers et al. 1999; Moir et al. 2000; Shimi et al. 2008). In addition, FCS data demonstrate that within the nucleoplasm, B-type lamins are less mobile, whereas the majority of A-type lamins reside in two mobile fractions, one fast and one slow moving (Shimi et al. 2008). The estimated molecular masses of these mobile fractions range from $\sim 1.3 \mathrm{MDa}$ (fast) to $\sim 0.8-2.9 \mathrm{GDa}$ (slow). Interestingly, the slow-moving lamin A fraction appears to be dependent on the presence of lamin B1, because downregulation of lamin B1 leads to a twofold increase in the mobility of this fraction. However, it is not clear if these mobile fractions represent polymers exclusively composed of lamins or lamin-containing multiprotein complexes. Further support for the association of nucleoplasmic Atype lamins with more dynamic structures that reside in lower assembly states comes from their extractability following detergent treatment of cells (Moir et al. 2000; Muralikrishna et al. 2004; Naetar et al. 2008).

The most dramatic changes in the dynamic behavior of lamins occur during mitosis. To facilitate NE breakdown (NEBD) and subsequent disassembly of the nucleus in metazoan cells, the lamin meshworks are depolymerized (Heald and McKeon 1990; Collas 1998; Panorchan et al. 2004). This is achieved by sequential phosphorylation of lamins at specific sites by various mitotic kinases including cyclin-dependent kinase (Cdk) 1 and protein kinase C (PKC) (Heald and McKeon 1990; Peter et al. 1990; Ward and Kirschner 1990; Fields and Thompson 1995; Collas 1999; Kuga et al. 2010). During this process, A-type lamins become solubilized and first accumulate within the nuclear interior and later, following NEBD, disperse throughout the cytoplasm (Georgatos et al. 1997; Dechat et al. 2007). In contrast, B-type lamins remain associated with the NE until NEBD and subsequently become distributed throughout the cytoplasm, partly soluble and partly membrane associated (Meier and Georgatos 1994; Georgatos et al. 1997; Beaudouin et al. 2002; Dechat et al. 2007). A- and B-type lamins also behave differently during nuclear reassembly at the end of mitosis. Whereas B-type lamins relocalize exclusively to the newly forming NE, A-type lamins initially relocalize to a spatially defined structure at the surface of the segregating sister chromatids, called "core" region, and subsequently accumulate within the nuclear interior (Broers et al. 1999; Moir et al. 2000; Dechat et al. 2004, 2007; Haraguchi et al. 2008). During $G_{1}$ phase, A-type lamins are detected as mobile, unpolymerized components within the nucleoplasm and are gradually integrated into a stable polymer at the nuclear periphery as cells progress through $\mathrm{G}_{1}$ (Moir et al. 2000). Thus, A-type lamins, in particular, are found in the nuclear interior in $\mathrm{G}_{1}$ phase of cycling cells (Bridger et al. 1993; Dechat et al. 2000b). In contrast, in S-phase cells and during in vitro differentiation of myoblasts into myotubes, the nucleoplasmic pool of A-type lamins is greatly reduced (Muralikrishna et al. 2001; Markiewicz et al. 2005; Naetar and Foisner 2009). Importantly, the nucleoplasmic localization of A-type lamins has also been detected within whole tissues (Naetar et al. 2008), showing that nucleoplasmic lamins are not just an artifact of in vitro cell cultures. Although proliferating progenitor cells in the mouse epidermis contain nucleoplasmic A-type lamins, nonproliferating, differentiated cells in the suprabasal layers of the epidermis are depleted of the nucleoplasmic lamin pool.

In addition to A-type lamins, B-type lamins have also been reported to localize in the nuclear interior either in nucleoplasmic foci, where they colocalize with sites of DNA replication (Moir et al. 1994), or are diffusely distributed (Moir et al. 2000). In contrast to the mobile nucleoplasmic A-type lamins, B-type lamins residing within the nuclear interior are immobile, similar to those integrated in the nuclear lamina, and therefore suggested to be associated with more stable structures (Moir et al. 2000; Shimi et al. 2008).

\section{REGULATION OF NUCLEOPLASMIC LAMINS}

The fact that A-type lamins accumulate in the nuclear interior at the end of mitosis and during $\mathrm{G}_{1}$ phase and that nucleoplasmic lamin A was detected in tissues only in proliferating progenitor cells leads to the hypothesis that the nucleoplasmic pool of lamin A represents intermediates of lamin A complexes during their assembly into the lamina after mitosis (Fig. 2). In this scenario, the lamina-independent pool of lamins in $G_{1}$ phase is generated in the preceding mitosis, but there are also other possibilities. For example, newly synthesized prelamin A initially localizes in the nuclear interior after its import into the nucleus (Goldman et al. 1992; Lutz et al. 1992; Dyer et al. 1999) and is posttranslationally modified at its carboxyl terminus with a hydrophobic farnesyl residue. The latter 


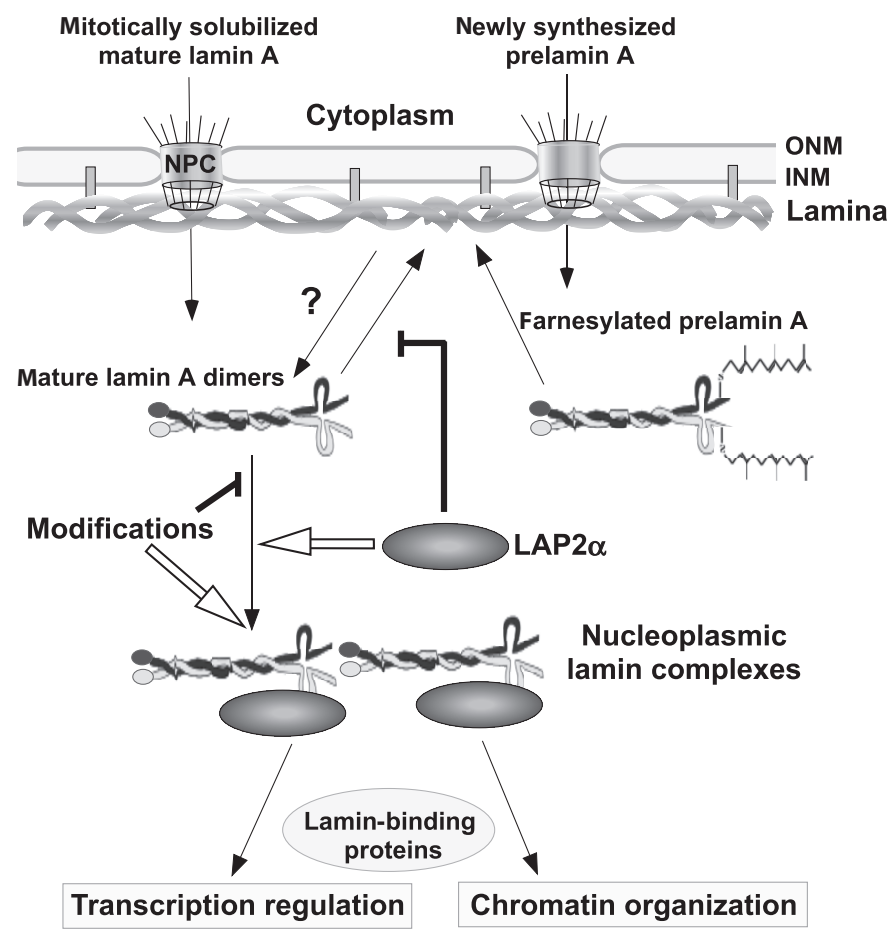

Figure 2. Potential regulation of nucleoplasmic lamins. Mitotically solubilized, mature lamin and newly synthesized prelamin A are imported into the nucleus through NPCs. Prelamin A is processed and finally integrated into the lamina. Mature lamin either polymerizes into the lamina or is retained in the nucleoplasm with the help of LAP2 $\alpha$ and, likely, specific modifications. Nucleoplasmic LAP2 $\alpha$-lamin complexes serve important functions in gene expression and chromatin organization. (ONM) Outer nuclear membrane, (INM) inner nuclear membrane.

leads to its translocation to the INM, where the last 15 amino acids containing the farnesyl group are cleaved off by Zmpste24/FACE1, a protease residing in the ER and INM (Lehner et al. 1986; Lutz et al. 1992; Sinensky et al. 1994; Barrowman et al. 2008). Fully processed, mature lamin A is then assembled into the lamina (Fig. 2). Therefore, newly synthesized lamin A within the nuclear interior most likely comprises prelamin A and farnesylated prelamin A, but not mature lamin A. The half-life of these two prelamin A forms in the nucleoplasm may range from less than 30 min to $3 \mathrm{~h}$ (Lehner et al. 1986; Goldman et al. 1992; Lutz et al. 1992), and it is unclear whether their nucleoplasmic localization is only related to posttranslational processing or also specific cellular functions.

The third possibility is a dynamic exchange of lamin subunits between the filamentous lamina and nucleoplasmic pool (Fig. 2). This mechanism has been previously demonstrated for cytoplasmic keratin and vimentin IFs (for review, see Eriksson et al. 2009), but has not yet been proven experimentally for lamins.

Independent of which of these pathways is relevant for lamins in the nucleoplasm, the lamina-independent pool has to be regulated in some way. What keeps a certain fraction of A-type lamins in the nucleoplasm in $G_{1}$ phase and prevents it from rapid polymerization and incorporation into the lamina? First insights into the potential regulation of nucleoplasmic lamins come from a recent study on a lamin-binding protein termed lamina-associated polypeptide (LAP) $2 \alpha$ (Naetar et al. 2008).
LAP2 $\alpha$ is one of six splice variants in mammals encoded by the LAP2 gene (Harris et al. 1995). Although most LAP2 isoforms are transmembrane proteins of the INM interacting with B-type lamins, LAP2 $\alpha$ localizes throughout the nuclear interior, because it misses a transmembrane domain, and interacts specifically with A-type lamins in vitro and in situ (see Dechat et al. 2000b; for review, see Dechat et al. 2000a). Genetic ablation of Lap $2 \alpha$ in mice reveals that the nucleoplasmic pool of A-type lamins is lost in proliferating primary fibroblasts derived from LAP2 $\alpha$-deficient mice (Fig. 3 ) as well as in proliferating progenitor cells in the epidermis of LAP $2 \alpha$-deficient mice (Naetar et al. 2008). Importantly, expression of LAP $2 \alpha$, but not of a LAP $2 \alpha$ mutant deficient in lamin $\mathrm{A} / \mathrm{C}$ binding, can rescue the nucleoplasmic pool of A-type lamins in the LAP $2 \alpha$-deficient fibroblasts. In addition, the siRNA-mediated knockdown of LAP2 $\alpha$ in primary human dermal fibroblasts also led to a decrease in nucleoplasmic lamins (Pekovic et al. 2007). These results led to the hypothesis that LAP $2 \alpha$ is essential and sufficient for targeting or stabilizing lamins $\mathrm{A} / \mathrm{C}$ within the nuclear interior (Fig. 2). In line with this hypothesis is the finding that following myoblast differentiation, the loss of nucleoplasmic lamins goes hand in hand with a down-regulation of LAP2 $\alpha$ (Markiewicz et al. 2005).

It is still unclear how LAP2 $\alpha$ prevents lamin A/C assembly and integration into the lamina (Fig. 2). A clue for a potential mechanism comes from a recent study on importin- $\alpha /$ Xenopus lamin B3 (XLB3) complexes (Adam et 


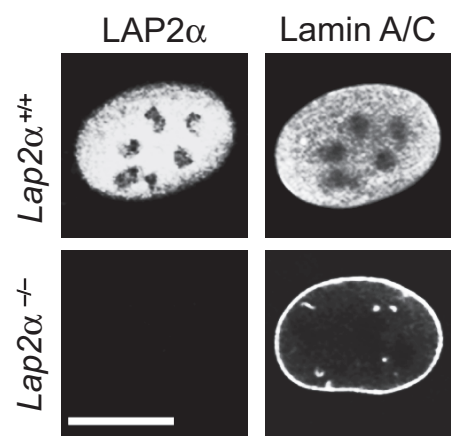

Figure 3. Indirect immunofluorescence microscopy of mouse primary fibroblasts derived from wild-type $\left(\right.$ Lap $\left.2 \alpha^{+/+}\right)$or LAP $2 \alpha$-deficient $\left(\right.$ Lap $\left.2 \alpha^{--}\right)$mice depicting LAP $2 \alpha$ (left $)$ and lamins A/C (right). Bar, $10 \mu \mathrm{m}$.

al. 2008). This study shows that the interaction of $X$ LB3 with importin- $\alpha$ inhibits $X \mathrm{LB} 3$ polymerization in vitro and prevents the assembly of $X \mathrm{LB} 3$ into the lamina in Xenopus egg extract nuclear assembly assays. Furthermore, this interaction is dependent on the presence of the NLS in $X \mathrm{LB} 3$ and can be inhibited by RanGTP. Similar to the situation regarding the importin- $\alpha / X \mathrm{LB} 3$ interaction, the binding of LAP $2 \alpha$ to the amino-terminal tail of lamins A/C (Fig. 1) (Dechat et al. 2000b) might counteract lamin polymerization.

Despite the important role of LAP2 $\alpha$ in targeting lamins $\mathrm{A} / \mathrm{C}$ in the nuclear interior, additional cell-cycledependent regulatory pathways likely exist based on the following observation. In immunofluorescence microscopy, LAP $2 \alpha$ localizes in the nucleoplasm in proliferating cells throughout the cell cycle, yet nucleoplasmic lamins $\mathrm{A} / \mathrm{C}$ are only detectable in $\mathrm{G}_{1}$ phase and are lost in late S phase (Naetar and Foisner 2009). These results are consistent with several models: For example, nucleoplasmic lamin A may change its conformation or interaction partners following progression from $\mathrm{G}_{1}$ to $\mathrm{S}$ phase, causing the masking of antibody epitopes, as suggested previously in other cases (Dyer et al. 1997; Tunnah et al. 2005). However, our observations that nucleoplasmic lamins are undetectable in $\mathrm{S}$ phase by various antibodies reacting with different lamin domains makes this scenario unlikely (Dechat et al. 2000b; Dechat et al., unpubl.). We therefore speculate that modifications of lamins and/or LAP2 $\alpha$ may regulate their interactions and localization (Figs. 1 and 2).

Lamin phosphorylation has long been known to regulate lamin disassembly during mitosis, and dephosphorylation of lamins by protein phosphatase 1 at the end of mitosis is required for their assembly into the nuclear lamina (Thompson et al. 1997; Steen et al. 2000). It is also known that lamins are phosphorylated during interphase (Eggert et al. 1993; Schneider et al. 1999; Otto et al. 2001; Kuga et al. 2010), but besides a potential phosphorylationdependent regulation of nuclear import (Hennekes et al. 1993; Leukel and Jost 1995), the effects of interphase-specific lamin phosphorylation remain to be elucidated. In addition to phosphorylation and farnesylation/carboxymethylation, lamin A is also modified by ADP ribosylation (Adolph 1987), sumoylation (Zhang and Sarge 2008), and probably glycosylation (Ferraro et al. 1989) and acetylation (Kim et al. 2006; Choudhary et al. 2009). However, only for sumoylation has the modified residue in lamins $\mathrm{A} / \mathrm{C}$ (lysine 201) and its functional relevance been reported. Regarding the latter, mutations within the sumoylation consensus sequence in lamin A associated with familial dilated cardiomyopathy lead to a decrease in lamin A sumoylation, an altered nuclear localization of lamin A, and an increase in cell death (Zhang and Sarge 2008). In addition to lamins, LAP2 $\alpha$ is also phosphorylated (Gajewski et al. 2004) and potentially acetylated (Choudhary et al. 2009) in interphase. However, it is unknown whether these modifications affect the interaction of LAP2 $\alpha$ with lamins A/C.

\section{FUNCTIONS OF LAMINS WITHIN THE NUCLEAR INTERIOR}

Although previous studies suggested that the presence of nucleoplasmic A-type lamins is simply a consequence of their specific assembly pathway after mitosis, more recent data also indicate roles of the nucleoplasmic lamin pool in various cellular processes (see below). Nevertheless, there are still numerous open questions: Do internal lamins have specific functions that do not overlap with those of the peripheral lamina? Do nucleoplasmic lamins provide scaffolding platforms for components of signaling pathways, similar to what has been described for the lamina, or do they actively engage in regulatory pathways?

Most of the newly reported functions of lamins, both at the NE and in the nuclear interior, are based on the identification of novel interaction partners of lamins, including cell cycle regulators, transcription factors, and proteins involved in chromatin organization (Fig. 1) (Dorner et al. 2007; Vlcek and Foisner 2007). However, in many cases the physiological significance of these interactions must still be demonstrated. Below, we discuss the best-studied processes, in which nucleoplasmic lamins are likely involved.

- Nucleoplasmic lamins in gene transcription, cell cycle progression, and differentiation. Retinoblastoma protein $(\mathrm{pRb})$, the major cell cycle regulator protein and transcriptional repressor, has been shown to bind to both A-type lamins and LAP2 $\alpha$ (Ozaki et al. 1994; Markiewicz et al. 2002a, 2005). pRb's major activity in cell cycle control is its interaction with and inhibition of E2F-type transcription factors in $\mathrm{G}_{1}$ phase, which facilitates cell cycle exit (Giacinti and Giordano 2006). Hyperphosphorylation of $\mathrm{pRb}$ by cyclin-dependent kinases causes its release from and subsequent activation of E2F, which in turn drives the expression of E2F target genes necessary for cell cycle progression. Although original studies suggested that nucleoplasmic lamin A/C-LAP $2 \alpha$ complexes are important for the anchorage and localization of $\mathrm{pRb}$ in the nucleus (Markiewicz et al. 2002a; Pekovic et al. 2007), other studies of lamin $\mathrm{A} / \mathrm{C}$ knockout cells found lamins $\mathrm{A} / \mathrm{C}$ to be important for $\mathrm{pRb}$ protein stability (Johnson et al. 2004; Nitta et al. 2006). More recent studies show additional roles of lamin A/C-LAP2 $\alpha$ in the control of pRb activity (Dorner et al. 2006; Naetar et al. 2008). 
LAP $2 \alpha$ and lamins A/C primarily bind hypophosphorylated $\mathrm{pRb}$ at $\mathrm{E} 2 \mathrm{~F}$ promoter sequences and mediate efficient $\mathrm{pRb}$-dependent repression of E2F target genes (Mancini et al. 1994; Markiewicz et al. 2002a; Dorner et al. 2006; Pekovic et al. 2007). Thus, complexes of nucleoplasmic lamins $\mathrm{A} / \mathrm{C}$ and LAP $2 \alpha$ have been proposed to serve as cell cycle regulators that promote cell cycle exit by enhancing $\mathrm{pRb}$ repressor activity. This model is supported by the observation that in LAP $2 \alpha-$ deficient epidermis and cells, which both lack nucleoplasmic lamins $\mathrm{A} / \mathrm{C}$, pRb activity is compromised and progenitor cells show hyperproliferation and delayed differentiation (Pekovic et al. 2007; Naetar et al. 2008). Similar effects were detected in lamin A/C-deficient epidermis (Naetar et al. 2008). However, it is not completely clear how LAP $2 \alpha$-lamin A/C affects pRb activity mechanistically. One possibility is that the complex regulates $\mathrm{pRb}$ (de)phosphorylation. This hypothesis is in line with a report showing that TGF $\beta$-mediated cell cycle arrest (which requires PP2A-dependent dephosphorylation of $\mathrm{pRb}$ ) is less efficient in lamin A-deficient cells due to an impaired $\mathrm{pRb}$ dephosphorylation (Van Berlo et al. 2005). The latter model is consistent with a scaffolding role of nucleoplasmic lamin $\mathrm{A} / \mathrm{C}$ complexes allowing efficient recruitment of regulatory enzymes of specific pathways. However, a more direct role of lamin A in transcriptional repression is also possible, as indicated by findings that artificial targeting of lamin A to a promoter of a reporter gene mediates its efficient repression (Lee et al. 2009).

Because both LAP2 $\alpha$-deficient (Gotic et al. 2010) and lamin A-deficient (Frock et al. 2006) mouse myoblasts (or myoblasts expressing an EDMD-causing lamin A mutant) (Favreau et al. 2004) show impaired differentiation in vitro, it is possible that lamin $\mathrm{A} / \mathrm{C}$ LAP $2 \alpha$ complexes also regulate muscle-specific $\mathrm{pRb}$ activity (Gotic and Foisner 2010), which is required during early muscle differentiation (Huh et al. 2004). This is supported by expression-profiling analyses of muscle biopsies from lamin-linked EDMD patients, which revealed an impairment of the $\mathrm{pRb}-\mathrm{MyoD}$ pathway in muscle regeneration (Bakay et al. 2006). In addition, lamin A has also been shown to interact directly with cyclin D3 (Mariappan et al. 2007), which was found to reorganize lamins $\mathrm{A} / \mathrm{C}$ during myoblast to myotube conversion in a pRb-dependent manner (Mariappan and Parnaik 2005). Thus, nucleoplasmic lamins may have multiple roles in regulating $\mathrm{pRb}$-linked pathways during myogenic differentiation.

Lamin A also interacts with other differentiationspecific transcription factors, such as the sterol response-element-binding protein (SREBP) 1 (Lloyd et al. 2002) and the zinc-finger transcription factor MOK2 (Dreuillet et al. 2002). Because both transcription factors localize primarily in the nucleoplasm (Kim and Spiegelman 1996; Arranz et al. 1997; Capanni et al. 2005; Dreuillet et al. 2008), it is likely that they mostly interact with lamins $\mathrm{A} / \mathrm{C}$ in the nuclear interior. However, besides a mislocalization of these transcription factors following the expression of pathogenic lamin A mutants (Capanni et al. 2005; Hubner et al. 2006; Dreuillet et al. 2008), the role of lamins A/C in regulating these complexes is not clear yet.

Lamins have also been implicated in the control of gene expression by influencing upstream components or transcriptional coregulators of various signaling pathways, such as the Notch and the ERK pathway (Espada et al. 2008; Favreau et al. 2008; Gonzalez et al. 2008; Scaffidi and Misteli 2008; Emerson et al. 2009; Muchir et al. 2009). It has been proposed that scavenging of signaling molecules (ERK) and transcriptional regulators (c-Fos, SKIP) at the lamina may either inhibit the pathway by preventing their binding to respective promoters (Ivorra et al. 2006; Scaffidi and Misteli 2008) or facilitate signaling by mediating activating reactions (e.g., ERK-mediated activation of c-Fos; Gonzalez et al. 2008). In principle, however, all of these interactions of signaling components with lamins could also occur in the nuclear interior. In fact, many of the regulatory functions attributed to peripheral lamins in previous studies may be accomplished at least in part by the nucleoplasmic pool.

- Nucleoplasmic lamins in chromatin organization. In vertebrates, the nuclear lamina has been proposed to generate a heterochromatic "gene silencing" environment at the nuclear periphery (Guelen et al. 2008). However, translocation of a reporter gene to the nuclear periphery does not always mediate its repression. Whereas tethering genes to lamin-binding integral INM proteins emerin or LAP2 $\beta$ led to full or partial transcriptional repression (Finlan et al. 2008; Reddy et al. 2008), tethering by lamin B1 did not affect transcription (Kumaran and Spector 2008). With respect to nucleoplasmic lamins, little is known about their potential roles in chromatin organization. However, because lamins have been reported to bind DNA and histones (for review, see Dechat et al. 2009), the histone-binding proteins RBBP4/7 (Pegoraro et al. 2009) and ING1 (Han et al. 2008), and the DNA cross-linking protein barrier-to-autointegration factor (BAF) (Holaska et al. 2003; Haraguchi et al. 2007), it is conceivable that lamins in the nuclear interior contribute to chromatin organization and epigenetic gene regulation. In line with this hypothesis, ING1 mislocalizes to the cytoplasm in lamin A/C-deficient cells (Han et al. 2008), and nucleoplasmic levels of RBBP4/7 are decreased in fibroblasts expressing a lamin A mutant associated with HGPS (Pegoraro et al. 2009). These findings suggest that nucleoplasmic lamins may provide a platform for chromatin-associated/remodeling proteins and thereby regulate their stability, localization, and/or activity.

In particular, the LAP $2 \alpha$-lamin A complex may be involved in chromatin organization within the nuclear interior, because LAP $2 \alpha$ itself interacts with chromatin by several means: a carboxy-terminal chromatin targeting domain (Vlcek et al. 1999) and an amino-terminal LAP2, emerin, MAN1 (LEM) and LEM-like domain (Cai et al. 2001). The LEM motif is found in a group of chromatin-associated proteins, mostly localized in the INM (for review, see Wilson and Foisner 2010), and 
mediates binding to BAF, whereas the LEM-like motif directly binds DNA (Cai et al. 2001). Thus, a multitude of interactions of the LAP $2 \alpha$-lamin A complex with DNA and chromatin proteins may contribute to their potential role in chromatin organization and/or gene regulation.

- Nucleoplasmic lamins in other cellular functions. Support for a role of lamins in DNA replication comes from the findings that lamin A localizes to intranuclear early-replication foci (Kennedy et al. 2000) and that lamins interact directly with the proliferating cellular nuclear antigen (PCNA), a component of the replication machinery (Shumaker et al. 2008), although the molecular mechanisms are still unclear.

Other proteins present within the nucleoplasm and reported to interact with lamins $\mathrm{A} / \mathrm{C}$ in vitro include PKC (Martelli et al. 2000, 2002), nuclear actin (Sasseville and Langelier 1998; for reviews, see Shumaker et al. 2003; Maraldi et al. 2004; Mehta et al. 2008), and a protein termed Lamin companion (Lco1) (Vlcek et al. 2004). However, the physiological role of these interactions is yet to be determined.

\section{ROLE OF NUCLEOPLASMIC LAMINS IN THE DEVELOPMENT OF LAMINOPATHIES}

Within the last 10 years, several human diseases now called laminopathies have been linked to mutations in lamin genes, primarily $L M N A$, and in genes encoding proteins associated with lamins (Worman et al. 2010). Studying the various laminopathies helped tremendously in identifying novel functions of lamins (see above), yet the molecular disease mechanisms are still poorly understood. Disease-causing mutations have been proposed to impair lamin assembly (affecting lamin complex stability) or lamin interactions (interfering with their specific role in signaling) (for reviews, see Parnaik 2008; Andres and Gonzalez 2009; Prokocimer et al. 2009; Dechat et al. 2010). Interestingly, many laminopathy-causing mutations are single-point mutations in $L M N A$, distributed along the whole lamin A/C coding sequence (Fig. 1) and leading to the expression of a mutated protein with a single amino acid exchange. These mutated lamins are often mislocalized in nucleoplasmic foci/aggregates or are distributed diffusely in the nucleoplasm (for examples, see Östlund et al. 2001; Muchir et al. 2004; Hubner et al. 2006; Wiesel et al. 2008). Furthermore, the most prominent HGPS-linked lamin mutation induces missplicing of the LMNA transcript and generates a permanently farnesylated prelamin A variant tightly tethered to the INM (Dechat et al. 2007). Thus, many disease-linked mutations affect the localization of $\operatorname{lamin} \mathrm{A}$, either increasing or decreasing the nucleoplasmic pool of lamin A (for examples, see Markiewicz et al. 2002b; Gilchrist et al. 2004; Muchir et al. 2004; Broers et al. 2005; Dahl et al. 2006; Hubner et al. 2006; Wiesel et al. 2008) and it is conceivable that at least some of the pathologies of these diseases are linked to a misregulation of the functions of nucleoplasmic lamins in, e.g., gene expression, cell cycle progression, and chromatin organization (Gotzmann and Foisner 2006). In line with this hy- pothesis, HGPS fibroblasts show heterochromatin loss and impairment of epigenetic pathways (Goldman et al. 2004; Shumaker et al. 2006) and misregulation of adult stem cell differentiation (Scaffidi and Misteli 2008), and mouse models of progeria show stem cell defects in the epidermis (Espada et al. 2008).

Intriguingly, lamin-mediated pathways, likely also those mediated by nucleoplasmic lamins, appear to have a role in normal aging, because the mutant lamin protein associated with HGPS and/or farnesylated prelamin A are also found enriched in cells of healthy elder individuals (Scaffidi and Misteli 2006; Cao et al. 2007; McClintock et al. 2007; Rodriguez et al. 2009).

\section{CONCLUSIONS}

Since the discovery of lamins in the late 1970s, and their subsequent cloning and identification as IF proteins in the 1980 s, research on lamins has gone through several periods of excitement but also periods of disinterest. After the initial boom during the analyses of their biochemical properties, in which lamins were recognized as mostly structural components of the nucleus, many scientists interested in development- and disease-relevant cellular processes turned away from the field. With the discovery of an increasing number of mutations in lamins that are linked to human diseases, starting in 1999, and the report of an unexpected muscle phenotype in the first lamin knockout mouse model, a second wave of excitement began. During the last 10 years, numerous novel and often unexpected functions of lamins in chromatin organization, gene expression, and cell signaling have been reported and much still must be done to study the mechanistic details of these functions and their relevance for human diseases. In more recent years, investigators also started to realize that the function of lamins is not only restricted to the nuclear periphery; lamins seem to have important regulatory roles throughout the entire nucleus. Yet, mostly because lamins in the nuclear interior are not abundant and thus difficult to study, reports on their assembly state, regulation, and functions are just beginning to emerge. In the future, we will have to revisit whether some of the functions previously attributed to the lamina, particularly those involved in signaling pathways and gene expression, are also linked to the nucleoplasmic lamin pool.

\section{ACKNOWLEDGMENTS}

We thank Nana Naetar for providing images shown in Fig. 3. We gratefully acknowledge grant support from the Austrian Science Research Fund (FWF P17871 and P22043) and the EURO-Laminopathies research project of the European Commission (Contract LSHM-CT-2005018690) to R.F.

\section{REFERENCES}

Adam SA, Sengupta K, Goldman RD. 2008. Regulation of nuclear lamin polymerization by importin $\alpha$. J Biol Chem 283: 8462 8468.

Adolph KW. 1987. ADPribosylation of nuclear proteins labeled 
with $[3 \mathrm{H}]$ adenosine: Changes during the HeLa cycle. Biochim Biophys Acta 909: 222-230.

Aebi U, Cohn J, Buhle L, Gerace L. 1986. The nuclear lamina is a meshwork of intermediate-type filaments. Nature 323: 560-564.

Andres V, Gonzalez JM. 2009. Role of A-type lamins in signaling, transcription, and chromatin organization. J Cell Biol 187: 945957.

Arranz V, Harper F, Florentin Y, Puvion E, Kress M, Ernoult-Lange M. 1997. Human and mouse MOK2 proteins are associated with nuclear ribonucleoprotein components and bind specifically to RNA and DNA through their zinc finger domains. Mol Cell Biol 17: 2116-2126.

Bakay M, Wang Z, Melcon G, Schiltz L, Xuan J, Zhao P, Sartorelli V, Seo J, Pegoraro E, Angelini C, et al. 2006. Nuclear envelope dystrophies show a transcriptional fingerprint suggesting disruption of Rb-MyoD pathways in muscle regeneration. Brain 129: 996-1013.

Barboro P, D'Arrigo C, Diaspro A, Mormino M, Alberti I, Parodi S, Patrone E, Balbi C. 2002. Unraveling the organization of the internal nuclear matrix: RNA-dependent anchoring of NuMA to a lamin scaffold. Exp Cell Res 279: 202-218.

Barboro P, D’Arrigo C, Repaci E, Patrone E, Balbi C. 2010. Organization of the lamin scaffold in the internal nuclear matrix of normal and transformed hepatocytes. Exp Cell Res 316: 9921001.

Barrowman J, Hamblet C, George CM, Michaelis S. 2008. Analysis of prelamin A biogenesis reveals the nucleus to be a CaaX processing compartment. Mol Biol Cell 19: 5398-5408.

Beaudouin J, Gerlich D, Daigle N, Eils R, Ellenberg J. 2002. Nuclear envelope breakdown proceeds by microtubule-induced tearing of the lamina. Cell 108: 83-96.

Belmont AS, Zhai Y, Thilenius A. 1993. Lamin B distribution and association with peripheral chromatin revealed by optical sectioning and electron microscopy tomography. J Cell Biol 123: 1671-1685.

Ben-Harush K, Wiesel N, Frenkiel-Krispin D, Moeller D, Soreq E, Aebi U, Herrmann H, Gruenbaum Y, Medalia O. 2009. The supramolecular organization of the C. elegans nuclear lamin filament. J Mol Biol 386: 1392-1402.

Bridger JM, Kill IR, O'Farrell M, Hutchison CJ. 1993. Internal lamin structures within $\mathrm{G}_{1}$ nuclei of human dermal fibroblasts. J Cell Sci 104: 297-306.

Broers JL, Machiels BM, van Eys GJ, Kuijpers HJ, Manders EM, van Driel R, Ramaekers FC. 1999. Dynamics of the nuclear lamina as monitored by GFP-tagged A-type lamins. J Cell Sci 112: 3463-3475.

Broers JL, Kuijpers HJ, Ostlund C, Worman HJ, Endert J, Ramaekers FC. 2005. Both lamin A and lamin C mutations cause lamina instability as well as loss of internal nuclear lamin organization. Exp Cell Res 304: 582-592.

Broers JL, Ramaekers FC, Bonne G, Yaou RB, Hutchison CJ. 2006. Nuclear lamins: Laminopathies and their role in premature ageing. Physiol Rev 86: 967-1008.

Butler JT, Hall LL, Smith KP, Lawrence JB. 2009. Changing nuclear landscape and unique PML structures during early epigenetic transitions of human embryonic stem cells. J Cell Biochem 107: 609-621.

Cai M, Huang Y, Ghirlando R, Wilson KL, Craigie R, Clore GM. 2001. Solution structure of the constant region of nuclear envelope protein LAP2 reveals two LEM-domain structures: One binds BAF and the other binds DNA. EMBO J 20: 4399-4407.

Cao K, Capell BC, Erdos MR, Djabali K, Collins FS. 2007. A lamin A protein isoform overexpressed in Hutchinson-Gilford progeria syndrome interferes with mitosis in progeria and normal cells. Proc Natl Acad Sci 104: 4949-4954.

Capanni C, Mattioli E, Columbaro M, Lucarelli E, Parnaik VK, Novelli G, Wehnert M, Cenni V, Maraldi NM, Squarzoni S, Lattanzi G. 2005. Altered pre-lamin A processing is a common mechanism leading to lipodystrophy. Hum Mol Genet 14: 1489-1502.

Choudhary C, Kumar C, Gnad F, Nielsen ML, Rehman M, Walther TC, Olsen JV, Mann M. 2009. Lysine acetylation targets protein complexes and co-regulates major cellular functions. Science 325: $834-840$.
Collas P. 1998. Nuclear envelope disassembly in mitotic extract requires functional nuclear pores and a nuclear lamina. J Cell Sci 111: 1293-1303.

Collas P. 1999. Sequential PKC- and Cdc2-mediated phosphorylation events elicit zebrafish nuclear envelope disassembly. $J$ Cell Sci 112: 977-987.

Constantinescu D, Gray HL, Sammak PJ, Schatten GP, Csoka AB. 2006. Lamin A/C expression is a marker of mouse and human embryonic stem cell differentiation. Stem Cells 24: 177-185.

Corrigan DP, Kuszczak D, Rusinol AE, Thewke DP, Hrycyna CA, Michaelis S, Sinensky MS. 2005. Prelamin A endoproteolytic processing in vitro by recombinant Zmpste24. Biochem J 387: 129-138.

Dahl KN, Scaffidi P, Islam MF, Yodh AG, Wilson KL, Misteli T. 2006. Distinct structural and mechanical properties of the nuclear lamina in Hutchinson-Gilford progeria syndrome. Proc Natl Acad Sci 103: 10271-10276.

Dechat T, Vlcek S, Foisner R. 2000a. Review: Lamina-associated polypeptide 2 isoforms and related proteins in cell cycle-dependent nuclear structure dynamics. J Struct Biol 129: 335-345.

Dechat T, Korbei B, Vaughan OA, Vlcek S, Hutchison CJ, Foisner R. 2000b. Lamina-associated polypeptide $2 \alpha$ binds intranuclear A-type lamins. J Cell Sci 113: 3473-3484.

Dechat T, Gajewski A, Korbei B, Gerlich D, Daigle N, Haraguchi T, Furukawa K, Ellenberg J, Foisner R. 2004. LAP2 $\alpha$ and BAF transiently localize to telomeres and specific regions on chromatin during nuclear assembly. J Cell Sci 117: 6117-6128.

Dechat T, Shimi T, Adam SA, Rusinol AE, Andres DA, Spielmann HP, Sinensky MS, Goldman RD. 2007. Alterations in mitosis and cell cycle progression caused by a mutant lamin A known to accelerate human aging. Proc Natl Acad Sci 104: 4955-4960.

Dechat T, Pfleghaar K, Sengupta K, Shimi T, Shumaker DK, Solimando L, Goldman RD. 2008. Nuclear lamins: Major factors in the structural organization and function of the nucleus and chromatin. Genes Dev 22: 832-853.

Dechat T, Adam SA, Goldman RD. 2009. Nuclear lamins and chromatin: When structure meets function. Adv Enzyme Regul 49: $157-166$.

Dechat T, Adam SA, Taimen P, Shimi T, Goldman RD. 2010. Nuclear lamins. Cold Spring Harb Perspect Biol 2: a000547.

Dhe-Paganon S, Werner ED, Chi YI, Shoelson SE. 2002. Structure of the globular tail of nuclear lamin. J Biol Chem 277: 1738117384.

Dorner D, Vlcek S, Foeger N, Gajewski A, Makolm C, Gotzmann J, Hutchison CJ, Foisner R. 2006. Lamina-associated polypeptide $2 \alpha$ regulates cell cycle progression and differentiation via the retinoblastoma-E2F pathway. J Cell Biol 173: 83-93.

Dorner D, Gotzmann J, Foisner R. 2007. Nucleoplasmic lamins and their interaction partners, LAP $2 \alpha, \mathrm{Rb}$, and BAF, in transcriptional regulation. FEBS J 274: 1362-1373.

Dreuillet C, Tillit J, Kress M, Ernoult-Lange M. 2002. In vivo and in vitro interaction between human transcription factor MOK2 and nuclear lamin A/C. Nucleic Acids Res 30: 4634-4642.

Dreuillet C, Harper M, Tillit J, Kress M, Ernoult-Lange M. 2008. Mislocalization of human transcription factor MOK2 in the presence of pathogenic mutations of lamin A/C. Biol Cell 100: 51-61.

Dyer JA, Lane BE, Hutchison CJ. 1999. Investigations of the pathway of incorporation and function of lamin A in the nuclear lamina. Microsc Res Tech 45: 1-12.

Dyer JA, Kill IR, Pugh G, Quinlan RA, Lane EB, Hutchison CJ. 1997. Cell cycle changes in A-type lamin associations detected in human dermal fibroblasts using monoclonal antibodies. Chromosome Res 5: 383-394.

Eggert M, Radomski N, Linder D, Tripier D, Traub P, Jost E. 1993. Identification of novel phosphorylation sites in murine A-type lamins. Eur J Biochem 213: 659-671.

Emerson LJ, Holt MR, Wheeler MA, Wehnert M, Parsons M, Ellis JA. 2009. Defects in cell spreading and ERK1/2 activation in fibroblasts with lamin A/C mutations. Biochim Biophys Acta 1792: $810-821$.

Eriksson JE, Dechat T, Grin B, Helfand B, Mendez M, Pallari HM, Goldman RD. 2009. Introducing intermediate filaments: From 
discovery to disease. J Clin Invest 119: 1763-1771.

Espada J, Varela I, Flores I, Ugalde AP, Cadinanos J, Pendas AM, Stewart CL, Tryggvason K, Blasco MA, Freije JM, Lopez-Otin C. 2008. Nuclear envelope defects cause stem cell dysfunction in premature-aging mice. $J$ Cell Biol 181: 27-35.

Favreau C, Higuet D, Courvalin JC, Buendia B. 2004. Expression of a mutant lamin A that causes Emery-Dreifuss muscular dystrophy inhibits in vitro differentiation of $\mathrm{C} 2 \mathrm{C} 12$ myoblasts. $\mathrm{Mol}$ Cell Biol 24: 1481-1492.

Favreau C, Delbarre E, Courvalin JC, Buendia B. 2008. Differentiation of $\mathrm{C} 2 \mathrm{C} 12$ myoblasts expressing lamin A mutated at a site responsible for Emery-Dreifuss muscular dystrophy is improved by inhibition of the MEK-ERK pathway and stimulation of the PI3-kinase pathway. Exp Cell Res 314: 1392-1405.

Ferraro A, Eufemi M, Cervoni L, Marinetti R, Turano C. 1989. Glycosylated forms of nuclear lamins. FEBS Lett 257: 241-246.

Fields AP, Thompson LJ. 1995. The regulation of mitotic nuclear envelope breakdown: A role for multiple lamin kinases. Prog Cell Cycle Res 1: 271-286.

Finlan LE, Sproul D, Thomson I, Boyle S, Kerr E, Perry P, Ylstra B, Chubb JR, Bickmore WA. 2008. Recruitment to the nuclear periphery can alter expression of genes in human cells. PLoS Genet 4: e1000039.

Foeger N, Wiesel N, Lotsch D, Mucke N, Kreplak L, Aebi U, Gruenbaum Y, Herrmann H. 2006. Solubility properties and specific assembly pathways of the B-type lamin from Caenorhabditis elegans. J Struct Biol 155: 340-350.

Fricker M, Hollinshead M, White N, Vaux D. 1997. Interphase nuclei of many mammalian cell types contain deep, dynamic, tubular membrane-bound invaginations of the nuclear envelope. $J$ Cell Biol 136: 531-544.

Frock RL, Kudlow BA, Evans AM, Jameson SA, Hauschka SD, Kennedy BK. 2006. Lamin A/C and emerin are critical for skeletal muscle satellite cell differentiation. Genes Dev 20: 486-500.

Gajewski A, Csaszar E, Foisner R. 2004. A phosphorylation cluster in the chromatin-binding region regulates chromosome association of LAP2 $\alpha$. J Biol Chem 279: 35813-35821.

Georgatos SD, Pyrpasopoulou A, Theodoropoulos PA. 1997. Nuclear envelope breakdown in mammalian cells involves stepwise lamina disassembly and microtubule-drive deformation of the nuclear membrane. J Cell Sci 110: 2129-2140.

Gerace L, Blobel G. 1980. The nuclear envelope lamina is reversibly depolymerized during mitosis. Cell 19: 277-287.

Giacinti C, Giordano A. 2006. RB and cell cycle progression. Oncogene 25: 5220-5227.

Gilchrist S, Gilbert N, Perry P, Ostlund C, Worman HJ, Bickmore WA. 2004. Altered protein dynamics of disease-associated lamin A mutants. BMC Cell Biol 5: 46.

Goldberg MW, Huttenlauch I, Hutchison CJ, Stick R. 2008. Filaments made from A- and B-type lamins differ in structure and organization. J Cell Sci 121: 215-225.

Goldman AE, Moir RD, Montag-Lowy M, Stewart M, Goldman RD. 1992. Pathway of incorporation of microinjected lamin A into the nuclear envelope. J Cell Biol 119: 725-735.

Goldman RD, Shumaker DK, Erdos MR, Eriksson M, Goldman AE, Gordon LB, Gruenbaum Y, Khuon S, Mendez M, Varga R, Collins FS. 2004. Accumulation of mutant lamin A causes progressive changes in nuclear architecture in Hutchinson-Gilford progeria syndrome. Proc Natl Acad Sci 101: 8963-8968.

Gonzalez JM, Navarro-Puche A, Casar B, Crespo P, Andres V. 2008. Fast regulation of AP-1 activity through interaction of lamin $\mathrm{A} / \mathrm{C}, \mathrm{ERK} 1 / 2$, and c-Fos at the nuclear envelope. $J$ Cell Biol 183: 653-666.

Gotic I, Foisner R. 2010. Multiple novel functions of lamina associated polypeptide $2 \alpha$ in striated muscle. Nucleus 1: 397-401.

Gotic I, Schmidt WM, Biadasiewicz K, Leschnik M, Spilka R, Braun J, Stewart CL, Foisner R. 2010. Loss of LAP2 $\alpha$ delays satellite cell differentiation and affects postnatal fiber-type determination. Stem Cells 28: 480-488.

Gotzmann J, Foisner R. 2006. A-type lamin complexes and regenerative potential: A step towards understanding laminopathic diseases? Histochem Cell Biol 125: 33-41.

Gruenbaum Y, Margalit A, Goldman RD, Shumaker DK, Wilson
KL. 2005. The nuclear lamina comes of age. Nat Rev Mol Cell Biol 6: 21-31.

Guelen L, Pagie L, Brasset E, Meuleman W, Faza MB, Talhout W, Eussen BH, de Klein A, Wessels L, de Laat W, van Steensel B. 2008. Domain organization of human chromosomes revealed by mapping of nuclear lamina interactions. Nature 453: 948 951.

Han X, Feng X, Rattner JB, Smith H, Bose P, Suzuki K, Soliman MA, Scott MS, Burke BE, Riabowol K. 2008. Tethering by lamin A stabilizes and targets the ING1 tumour suppressor. Nat Cell Biol 10: 1333-1340.

Haraguchi T, Koujin T, Osakada H, Kojidani T, Mori C, Masuda H, Hiraoka Y. 2007. Nuclear localization of barrier-to-autointegration factor is correlated with progression of S phase in human cells. J Cell Sci 120: 1967-1977.

Haraguchi T, Kojidani T, Koujin T, Shimi T, Osakada H, Mori C, Yamamoto A, Hiraoka Y. 2008. Live cell imaging and electron microscopy reveal dynamic processes of BAF-directed nuclear envelope assembly. J Cell Sci 121: 2540-2554.

Harris CA, Andryuk PJ, Cline SW, Mathew S, Siekierka JJ, Goldstein G. 1995. Structure and mapping of the human thymopoietin (TMPO) gene and relationship of human TMPO $\beta$ to rat lamin-associated polypeptide 2. Genomics 28: 198-205.

Heald R, McKeon F. 1990. Mutations of phosphorylation sites in lamin A that prevent nuclear lamina disassembly in mitosis. Cell 61: 579-589.

Heitlinger E, Peter M, Haner M, Lustig A, Aebi U, Nigg EA. 1991. Expression of chicken lamin B2 in Escherichia coli: Characterization of its structure, assembly, and molecular interactions. J Cell Biol 113: 485-495.

Hennekes H, Peter M, Weber K, Nigg EA. 1993. Phosphorylation on protein kinase $\mathrm{C}$ sites inhibits nuclear import of lamin B2. $J$ Cell Biol 120: 1293-1304.

Herrmann H, Strelkov SV, Burkhard P, Aebi U. 2009. Intermediate filaments: Primary determinants of cell architecture and plasticity. J Clin Invest 119: 1772-1783.

Holaska JM, Lee KK, Kowalski AK, Wilson KL. 2003. Transcriptional repressor germ cell-less (GCL) and barrier to autointegration factor (BAF) compete for binding to emerin in vitro. $J$ Biol Chem 278: 6969-6975.

Hozak P, Sasseville AM, Raymond Y, Cook PR. 1995. Lamin proteins form an internal nucleoskeleton as well as a peripheral lamina in human cells. J Cell Sci 108: 635-644.

Hubner S, Eam JE, Hubner A, Jans DA. 2006. Laminopathy-inducing lamin A mutants can induce redistribution of lamin binding proteins into nuclear aggregates. Exp Cell Res 312: 171-183.

Huh MS, Parker MH, Scime A, Parks R, Rudnicki MA. 2004. Rb is required for progression through myogenic differentiation but not maintenance of terminal differentiation. J Cell Biol 166: $865-876$.

Ivorra C, Kubicek M, Gonzalez JM, Sanz-Gonzalez SM, AlvarezBarrientos A, O’Connor JE, Burke B, Andres V. 2006. A mechanism of AP-1 suppression through interaction of c-Fos with lamin A/C. Genes Dev 20: 307-320.

Johnson BR, Nitta RT, Frock RL, Mounkes L, Barbie DA, Stewart CL, Harlow E, Kennedy BK. 2004. A-type lamins regulate retinoblastoma protein function by promoting subnuclear localization and preventing proteasomal degradation. Proc Natl Acad Sci 101: 9677-9682.

Karabinos A, Schunemann J, Meyer M, Aebi U, Weber K. 2003. The single nuclear lamin of Caenorhabditis elegans forms in vitro stable intermediate filaments and paracrystals with a reduced axial periodicity. J Mol Biol 325: 241-247.

Kennedy BK, Barbie DA, Classon M, Dyson N, Harlow E. 2000. Nuclear organization of DNA replication in primary mammalian cells. Genes Dev 14: 2855-2868.

Kim JB, Spiegelman BM. 1996. ADD1/SREBP1 promotes adipocyte differentiation and gene expression linked to fatty acid metabolism. Genes Dev 10: 1096-1107.

Kim Y, Sun Y, Chow C, Pommier YG, Simons SS Jr. 2006. Effects of acetylation, polymerase phosphorylation, and DNA unwinding in glucocorticoid receptor transactivation. J Steroid Biochem 
Mol Biol 100: 3-17.

Krimm I, Ostlund C, Gilquin B, Couprie J, Hossenlopp P, Mornon JP, Bonne G, Courvalin JC, Worman HJ, Zinn-Justin S. 2002. The Ig-like structure of the C-terminal domain of lamin A/C, mutated in muscular dystrophies, cardiomyopathy, and partial lipodystrophy. Structure 10: 811-823.

Krohne G, Waizenegger I, Hoger TH. 1989. The conserved carboxy-terminal cysteine of nuclear lamins is essential for lamin association with the nuclear envelope. J Cell Biol 109: 20032011.

Kuga T, Nozaki N, Matsushita K, Nomura F, Tomonaga T. 2010. Phosphorylation statuses at different residues of lamin B2, B1, and $\mathrm{A} / \mathrm{C}$ dynamically and independently change throughout the cell cycle. Exp Cell Res 316: 2301-2312.

Kumaran RI, Spector DL. 2008. A genetic locus targeted to the nuclear periphery in living cells maintains its transcriptional competence. J Cell Biol 180: 51-65.

Lee DC, Welton KL, Smith ED, Kennedy BK. 2009. A-type nuclear lamins act as transcriptional repressors when targeted to promoters. Exp Cell Res 315: 996-1007.

Lehner CF, Furstenberger G, Eppenberger HM, Nigg EA. 1986. Biogenesis of the nuclear lamina: In vivo synthesis and processing of nuclear protein precursors. Proc Natl Acad Sci 83: 2096 2099.

Leukel M, Jost E. 1995. Two conserved serines in the nuclear localization signal flanking region are involved in the nuclear targeting of human lamin A. Eur J Cell Biol 68: 133-142.

Lloyd DJ, Trembath RC, Shackleton S. 2002. A novel interaction between lamin A and SREBP1: Implications for partial lipodystrophy and other laminopathies. Hum Mol Genet 11: 769-777.

Loewinger L, McKeon F. 1988. Mutations in the nuclear lamin proteins resulting in their aberrant assembly in the cytoplasm. EMBO J 7: 2301-2309.

Lutz RJ, Trujillo MA, Denham KS, Wenger L, Sinensky M. 1992. Nucleoplasmic localization of prelamin A: Implications for prenylation-dependent lamin A assembly into the nuclear lamina. Proc Natl Acad Sci 89: 3000-3004.

Mancini MA, Shan B, Nickerson JA, Penman S, Lee WH. 1994. The retinoblastoma gene product is a cell cycle-dependent, nuclear matrix-associated protein. Proc Natl Acad Sci 91: 418-422.

Maraldi NM, Lattanzi G, Marmiroli S, Squarzoni S, Manzoli FA. 2004. New roles for lamins, nuclear envelope proteins and actin in the nucleus. Adv Enzyme Regul 44: 155-172.

Mariappan I, Parnaik VK. 2005. Sequestration of $\mathrm{pRb}$ by cyclin D3 causes intranuclear reorganization of lamin A/C during muscle cell differentiation. Mol Biol Cell 16: 1948-1960.

Mariappan I, Gurung R, Thanumalayan S, Parnaik VK. 2007. Identification of cyclin D3 as a new interaction partner of lamin A/C. Biochem Biophys Res Commun 355: 981-985.

Markiewicz E, Dechat T, Foisner R, Quinlan RA, Hutchison CJ. 2002a. Lamin A/C binding protein LAP2 $\alpha$ is required for nuclear anchorage of retinoblastoma protein. Mol Biol Cell 13: 4401-4413.

Markiewicz E, Venables R, Mauricio Alvarez R, Quinlan R, Dorobek M, Hausmanowa-Petrucewicz I, Hutchison C. 2002b. Increased solubility of lamins and redistribution of lamin $\mathrm{C}$ in $\mathrm{X}$-linked Emery-Dreifuss muscular dystrophy fibroblasts. $J$ Struct Biol 140: 241-253.

Markiewicz E, Ledran M, Hutchison CJ. 2005. Remodelling of the nuclear lamina and nucleoskeleton is required for skeletal muscle differentiation in vitro. J Cell Sci 118: 409-420.

Martelli AM, Tabellini G, Bortul R, Manzoli L, Bareggi R, Baldini G, Grill V, Zweyer M, Narducci P, Cocco L. 2000. Enhanced nuclear diacylglycerol kinase activity in response to a mitogenic stimulation of quiescent Swiss 3T3 cells with insulin-like growth factor I. Cancer Res 60: 815-821.

Martelli AM, Bortul R, Tabellini G, Faenza I, Cappellini A, Bareggi R, Manzoli L, Cocco L. 2002. Molecular characterization of protein kinase C- $\alpha$ binding to lamin A. J Cell Biochem 86: $320-330$.

McClintock D, Ratner D, Lokuge M, Owens DM, Gordon LB, Collins FS, Djabali K. 2007. The mutant form of lamin A that causes Hutchinson-Gilford progeria is a biomarker of cellular aging in human skin. PLOS ONE 2: e1269.

Mehta IS, Elcock LS, Amira M, Kill IR, Bridger JM. 2008. Nuclear motors and nuclear structures containing A-type lamins and emerin: Is there a functional link? Biochem Soc Trans 36: 1384-1388.

Meier J, Georgatos SD. 1994. Type B lamins remain associated with the integral nuclear envelope protein $\mathrm{p} 58$ during mitosis: Implications for nuclear reassembly. EMBO J 13: 1888-1898.

Melcer S, Gruenbaum Y, Krohne G. 2007. Invertebrate lamins. Exp Cell Res 313: 2157-2166.

Moir RD, Montag-Lowy M, Goldman RD. 1994. Dynamic properties of nuclear lamins: Lamin B is associated with sites of DNA replication. J Cell Biol 125: 1201-1212.

Moir RD, Yoon M, Khuon S, Goldman RD. 2000. Nuclear lamins $A$ and B1: Different pathways of assembly during nuclear envelope formation in living cells. J Cell Biol 151: 1155-1168.

Muchir A, Medioni J, Laluc M, Massart C, Arimura T, van der Kooi AJ, Desguerre I, Mayer M, Ferrer X, Briault S, et al. 2004. Nuclear envelope alterations in fibroblasts from patients with muscular dystrophy, cardiomyopathy, and partial lipodystrophy carrying lamin A/C gene mutations. Muscle Nerve 30: 444- 450.

Muchir A, Wu W, Worman HJ. 2009. Reduced expression of Atype lamins and emerin activates extracellular signal-regulated kinase in cultured cells. Biochim Biophys Acta 1792: 75-81.

Muralikrishna B, Dhawan J, Rangaraj N, Parnaik VK. 2001. Distinct changes in intranuclear lamin $\mathrm{A} / \mathrm{C}$ organization during myoblast differentiation. $J$ Cell Sci 114: 4001-4011.

Muralikrishna B, Thanumalayan S, Jagatheesan G, Rangaraj N, Karande AA, Parnaik VK. 2004. Immunolocalization of detergent-susceptible nucleoplasmic lamin $\mathrm{A} / \mathrm{C}$ foci by a novel monoclonal antibody. J Cell Biochem 91: 730-739.

Naetar N, Foisner R. 2009. Lamin complexes in the nuclear interior control progenitor cell proliferation and tissue homeostasis. Cell Cycle 8: 1488-1493.

Naetar N, Korbei B, Kozlov S, Kerenyi MA, Dorner D, Kral R, Gotic I, Fuchs P, Cohen TV, Bittner R, et al. 2008. Loss of nucleoplasmic LAP2 $\alpha$-lamin A complexes causes erythroid and epidermal progenitor hyperproliferation. Nat Cell Biol 10: 1341-1348.

Nitta RT, Jameson SA, Kudlow BA, Conlan LA, Kennedy BK. 2006. Stabilization of the retinoblastoma protein by A-type nuclear lamins is required for INK4A-mediated cell cycle arrest. Mol Cell Biol 26: 5360-5372.

Östlund C, Bonne G, Schwartz K, Worman HJ. 2001. Properties of lamin A mutants found in Emery-Dreifuss muscular dystrophy, cardiomyopathy and Dunnigan-type partial lipodystrophy. $J$ Cell Sci 114: 4435-4445.

Otto H, Dreger M, Bengtsson L, Hucho F. 2001. Identification of tyrosine-phosphorylated proteins associated with the nuclear envelope. Eur J Biochem 268: 420-428.

Ozaki T, Saijo M, Murakami K, Enomoto H, Taya Y, Sakiyama S. 1994. Complex formation between lamin A and the retinoblastoma gene product: Identification of the domain on lamin A required for its interaction. Oncogene 9: 2649-2653.

Panorchan P, Schafer BW, Wirtz D, Tseng Y. 2004. Nuclear envelope breakdown requires overcoming the mechanical integrity of the nuclear lamina. J Biol Chem 279: 43462-43467.

Parnaik VK. 2008. Role of nuclear lamins in nuclear organization, cellular signaling, and inherited diseases. Int Rev Cell Mol Biol 266: $157-206$.

Pederson T. 2010. The nucleus introduced. Cold Spring Harb Perspect Biol doi: 10.1101/cshperspect.a000521.

Pegoraro G, Kubben N, Wickert U, Gohler H, Hoffmann K, Misteli T. 2009. Ageing-related chromatin defects through loss of the NURD complex. Nat Cell Biol 11: 1261-1267.

Pekovic V, Harborth J, Broers JL, Ramaekers FC, van Engelen B, Lammens M, von Zglinicki T, Foisner R, Hutchison C, Markiewicz E. 2007. Nucleoplasmic LAP2 $\alpha$-lamin A complexes are required to maintain a proliferative state in human fibroblasts. J Cell Biol 176: 163-172.

Peter M, Nakagawa J, Doree M, Labbe JC, Nigg EA. 1990. In vitro disassembly of the nuclear lamina and $\mathrm{M}$ phase-specific phosphorylation of lamins by cdc2 kinase. Cell 61: 591-602.

Prokocimer M, Davidovich M, Nissim-Rafinia M, Wiesel-Motiuk 
N, Bar D, Barkan R, Meshorer E, Gruenbaum Y. 2009. Nuclear lamins: Key regulators of nuclear structure and activities. J Cell Mol Med 13: 1059-1085.

Reddy KL, Zullo JM, Bertolino E, Singh H. 2008. Transcriptional repression mediated by repositioning of genes to the nuclear lamina. Nature 452: 243-247.

Rober RA, Weber K, Osborn M. 1989. Differential timing of nuclear lamin $\mathrm{A} / \mathrm{C}$ expression in the various organs of the mouse embryo and the young animal: A developmental study. Development 105: 365-378.

Rodriguez S, Coppede F, Sagelius H, Eriksson M. 2009. Increased expression of the Hutchinson-Gilford progeria syndrome truncated lamin A transcript during cell aging. Eur J Hum Genet 17: 928-937.

Rusinol AE, Sinensky MS. 2006. Farnesylated lamins, progeroid syndromes and farnesyl transferase inhibitors. J Cell Sci 119: 3265-3272.

Sasseville AM, Langelier Y. 1998. In vitro interaction of the carboxy-terminal domain of lamin A with actin. FEBS Lett 425: 485-489.

Scaffidi P, Misteli T. 2006. Lamin A-dependent nuclear defects in human aging. Science 312: 1059-1063.

Scaffidi P, Misteli T. 2008. Lamin A-dependent misregulation of adult stem cells associated with accelerated ageing. Nat Cell Biol 10: 452-459.

Schermelleh L, Carlton PM, Haase S, Shao L, Winoto L, Kner P, Burke B, Cardoso MC, Agard DA, Gustafsson MG, Leonhardt H, Sedat JW. 2008. Subdiffraction multicolor imaging of the nuclear periphery with 3D structured illumination microscopy. Science 320: 1332-1336.

Schneider U, Mini T, Jeno P, Fisher PA, Stuurman N. 1999. Phosphorylation of the major Drosophila lamin in vivo: Site identification during both M-phase (meiosis) and interphase by electrospray ionization tandem mass spectrometry. Biochemistry 38: $4620-4632$.

Shimi T, Pfleghaar K, Kojima S, Pack CG, Solovei I, Goldman AE, Adam SA, Shumaker DK, Kinjo M, Cremer T, Goldman RD. 2008. The A- and B-type nuclear lamin networks: Microdomains involved in chromatin organization and transcription. Genes Dev 22: 3409-3421.

Shumaker DK, Kuczmarski ER, Goldman RD. 2003. The nucleoskeleton: Lamins and actin are major players in essential nuclear functions. Curr Opin Cell Biol 15: 358-366.

Shumaker DK, Dechat T, Kohlmaier A, Adam SA, Bozovsky MR, Erdos MR, Eriksson M, Goldman AE, Khuon S, Collins FS, et al. 2006. Mutant nuclear lamin A leads to progressive alterations of epigenetic control in premature aging. Proc Natl Acad Sci 103: $8703-8708$.

Shumaker DK, Solimando L, Sengupta K, Shimi T, Adam SA, Grunwald A, Strelkov SV, Aebi U, Cardoso MC, Goldman RD. 2008. The highly conserved nuclear lamin Ig-fold binds to PCNA: Its role in DNA replication. J Cell Biol 181: 269-280.

Sinensky M, Fantle K, Trujillo M, McLain T, Kupfer A, Dalton M. 1994. The processing pathway of prelamin A. J Cell Sci 107: 61-67.
Steen RL, Martins SB, Tasken K, Collas P. 2000. Recruitment of protein phosphatase 1 to the nuclear envelope by A-kinase anchoring protein AKAP149 is a prerequisite for nuclear lamina assembly. J Cell Biol 150: 1251-1262.

Stewart C, Burke B. 1987. Teratocarcinoma stem cells and early mouse embryos contain only a single major lamin polypeptide closely resembling lamin B. Cell 51: 383-392.

Stuurman N, Sasse B, Fisher PA. 1996. Intermediate filament protein polymerization: Molecular analysis of Drosophila nuclear lamin head-to-tail binding. J Struct Biol 117: 1-15.

Stuurman N, Heins S, Aebi U. 1998. Nuclear lamins: Their structure, assembly, and interactions. J Struct Biol 122: 42-66.

Svitkina TM, Verkhovsky AB, Borisy GG. 1995. Improved procedures for electron microscopic visualization of the cytoskeleton of cultured cells. J Struct Biol 115: 290-303.

Thompson LJ, Bollen M, Fields AP. 1997. Identification of protein phosphatase 1 as a mitotic lamin phosphatase. J Biol Chem 272: 29693-29697.

Tunnah D, Sewry CA, Vaux D, Schirmer EC, Morris GE. 2005. The apparent absence of lamin B1 and emerin in many tissue nuclei is due to epitope masking. J Mol Histol 36: 337-344.

Van Berlo JH, Voncken JW, Kubben N, Broers JL, Duisters R, van Leeuwen RE, Crijns HJ, Ramaekers FC, Hutchison CJ, Pinto YM. 2005. A-type lamins are essential for TGF- $\beta 1$ induced PP2A to dephosphorylate transcription factors. Hum Mol Genet 14: 2839-2849.

Verstraeten VL, Broers JL, Ramaekers FC, van Steensel MA. 2007. The nuclear envelope, a key structure in cellular integrity and gene expression. Curr Med Chem 14: 1231-1248.

Vlcek S, Foisner R. 2007. Lamins and lamin-associated proteins in aging and disease. Curr Opin Cell Biol 19: 298-304.

Vlcek S, Just H, Dechat T, Foisner R. 1999. Functional diversity of LAP $2 \alpha$ and LAP $2 \beta$ in postmitotic chromosome association is caused by an $\alpha$-specific nuclear targeting domain. EMBO J 18: 6370-6384.

Vlcek S, Foisner R, Wilson KL. 2004. Lco1 is a novel widely expressed lamin-binding protein in the nuclear interior. Exp Cell Res 298: 499-511.

Ward GE, Kirschner MW. 1990. Identification of cell cycle-regulated phosphorylation sites on nuclear lamin C. Cell 61: 561-577.

Wiesel N, Mattout A, Melcer S, Melamed-Book N, Herrmann H, Medalia O, Aebi U, Gruenbaum Y. 2008. Laminopathic mutations interfere with the assembly, localization, and dynamics of nuclear lamins. Proc Natl Acad Sci 105: 180-185.

Wilson KL, Foisner R. 2010. Lamin-binding proteins. Cold Spring Harb Perspect Biol 2: a000554.

Worman HJ, Ostlund C, Wang Y. 2010. Diseases of the nuclear envelope. Cold Spring Harb Perspect Biol 2: a000760.

Zhang YQ, Sarge KD. 2008. Sumoylation regulates lamin A function and is lost in lamin A mutants associated with familial cardiomyopathies. J Cell Biol 182: 35-39.

Zhang C, Jenkins H, Goldberg MW, Allen TD, Hutchison CJ. 1996. Nuclear lamina and nuclear matrix organization in sperm pronuclei assembled in Xenopus egg extract. J Cell Sci 109: 22752286. 


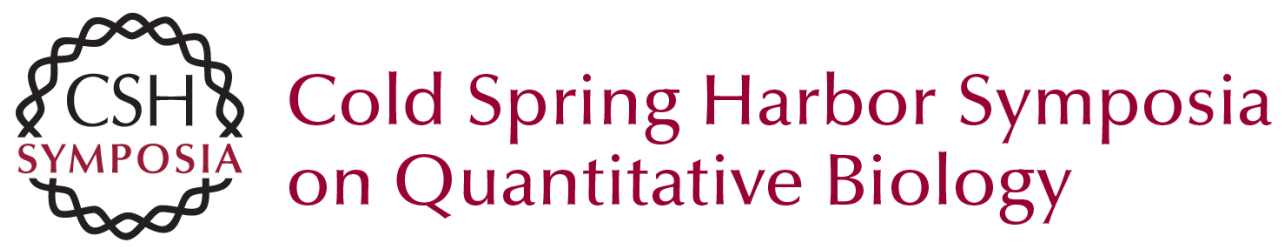

\section{Lamina-Independent Lamins in the Nuclear Interior Serve Important Functions}

T. Dechat, K. Gesson and R. Foisner

Cold Spring Harb Symp Quant Biol 2010 75: 533-543 originally published online January 5, 2011 Access the most recent version at doi:10.1101/sqb.2010.75.018

References This article cites 157 articles, 70 of which can be accessed free at: http://symposium.cshlp.org/content/75/533.full.html\#ref-list-1

\section{License}

Email Alerting Service top right corner of the article or click here. 